УДК 550.42:552.11(571.63)

ЛАНТАНОИДНЫЙ ТЕТРАДНЫЙ ЭФФЕКТ ФРАКЦИОНИРОВАНИЯ

РЕДКОЗЕМЕЛЬНЫХ ЭЛЕМЕНТОВ НА ПРИМЕРЕ

ЮЖНО-ЯКУТИНСКОЙ ВУЛКАНО-ТЕКТОНИЧЕСКОЙ СТРУКТУРЫ (ПРИМОРЬЕ, ДАЛЬНИЙ ВОСТОК РОССИИ)

\author{
Гребенникова А.А., Кузьмина Т.В. \\ Дальневосточный геологический институт ДВО РАН, Владивосток, \\ e-mail: anylotina@mail.ru
}

\begin{abstract}
Выявление тетрад-эффекта в магматических образованиях, несомненно, имеет ряд петрологических следствий, поскольку он связан с характерными аномальными параметрами флюидного режима в магматических системах, обогащенных летучими компонентами, в первую очередь $\mathrm{F}, \mathrm{H}, \mathrm{B}, \mathrm{CO}, \mathrm{P}$ и $\mathrm{Cl}$. Воздействие высокотемпературных флюидов на гомогенный гранитоидный расплав вызывает его гетерогенизацию и образование флюидонасыщенных расплавов, что приводит к перераспределению лантаноидов между несмесимыми жидкими фазами магмы и появлению тетрад-эффектов. «Тетрадный эффект» в различных геологических образованиях является одним из показателей рудогенерирующей способности магматических сред, поскольку, в частности, фторкомплексы служат важными переносчиками ряда рудообразующих элементов при формировании рудных гидротермальных месторождений - Sn, W, Mo, Be, Ta, Nb, Li и P3. Палеоценовые породы Южно-Якутинской вулкано-тектонической структуры (ВТС) Сихотэ-Алиня сложены кремнекислыми экструзивно-лавовыми и пирокластическими образованиями. Широкое развитие игнимбритов, развитие флюидальных и сферолитовых текстур в вулканических породах, наличие газовых полостей и миароловых пустот в лавах и сферолоидах свидетельствуют о насыщенности летучими компонентами исходных магм. Все это указывает на аномальные параметры флюидного режима в магматических расплавах. Следует отметить, что на прилегающих к ВТС площадях локализованы золото-серебряные и бериллиевые с флюоритом рудопроявления, а в пределах вулканитов самой ВТС отмечается повсеместная флюоритовая минерализация. В данной работе рассматривается наличие тетрад-эффекта в породах Южно-Якутинской ВТС как следствие флюидизации первичных магматических расплавов. Наиболее дифференцированные высококремнеземистые породы характеризуются самыми значимыми величинами тетрадного эффекта, в то время как в «низкокремнеземистых» величины $\mathrm{TE}_{1-3}$ менее выражены, но представляют собой наиболее F-обогащенные породы. Умеренные концентрации $\mathrm{F}$ в рассматриваемых риолитах не характеризуют его истинное начальное содержание. Фтор на поздней стадии перераспределяется исключительно во флюидную фазу, обедняя расплав по мере снижения температуры и концентрирования F в кристаллизующихся фторсодержащих минералах, что подтверждают экспериментальные исследования.
\end{abstract}

Ключевые слова: Южно-Якутинская ВТС, лантаноидный тетрадный эффект, риолиты, палеоцен, Сихотэ-Алинь

\title{
LANTHANIDE TETRAD EFFECT FRACTIONATION OF RARE EARTH ELEMENTS AS EXEMPLIFIED BY THE SOUTH YAKUT VOLCANIC DEPRESSION (PRIMORYE, RUSSIAN FAR EAST) \\ Grebennikova A.A., Kuzmina T.V. \\ Far East Geological Institute FEB RAS, Vladivostok, e-mail: anylotina@mail.ru
}

\begin{abstract}
Undoubtedly the detection of the tetrad effect in magmatic formations has a number of petrological consequences, since it is associated with the characteristic anomalous parameters of the fluid regime in the magmatic systems enriched with both the volatile components, and, first of all, with F, H, B, CO, P, and Cl. The effect of hightemperature fluids on a homogeneous granitoid melt causes the heterogenization of the last one and the formation of fluid-saturated melts, which leads to the redistribution of lanthanides between the immiscible liquid phases of granitoid magma being accompanied by the tetrad effect. The «tetrad effect» in various geological formations is one of the indicators of the ore-parent capacity of magmatic media, since in particular fluorocomplexes are important carriers (or hosts) of a number of ore-forming elements during the formation of ore hydrothermal deposits of tin, tungsten, molybdenum, beryllium, tantalum, niobium, lithium, and rare earth elements. Paleocene rocks of the South Yakut volcanic depression of Sikhote-Alin (Primorye) are composed of silicic acid extrusion-lava and pyroclastic formations. The widespread occurances of pyroclastic formations, the formation of the fluid and spherolitic textures in volcanic rocks, the presence of gas cavities and miarolic voids in lavas and spheroloids are the evidences of the saturation of the source magmas with volatile components. All this indicates abnormal parameters of the fluid regime in ignimbrite-forming melts. It should be noted that gold-silver and beryllium ore deposits with fluorite are localized in the areas adjacent to the volcanic depression, and the widespread fluorite mineralization is observed within the boundaries of the volcanites occurring on the territory of the volcanic depression. In this paper the presence of the tetrad effect in rocks of the South Yakut volcanic depression is considered to be caused by fluidization of primary magmatic melts. The most differentiated high-silica rocks are characterized by the most significant values of the tetrad effect. At the same time the «low-silica» ones demonstrate less remarkable values of TE1-3, being enriched with $\mathrm{F}$ to the higher degree. Moderate concentrations of $\mathrm{F}$ in the studied rhyolites do not characterize the genuine initial content of this element. At the last stage, fluorine is redistributed exclusively into the fluid phase, depleting the melt as the temperature decreases and $\mathrm{F}$ is concentrated in crystallizing fluorine-containing minerals, which is confirmed by the experimental studies.
\end{abstract}

Keywords: South Yakut volcanic depression, lanthanide tetrad effect, rhyolites, Sikhote-Alin (Primorye) 
Объектом исследования являются экструзивно-лавовые и пирокластические образования Южно-Якутинской вулканотектонической структуры (ВТС), расположенной в пределах южной части Восточного Сихотэ-Алиня в Кавалеровском рудном районе ( N $44^{\circ} 17^{\prime}$, E $\left.135^{\circ} 17^{\prime}\right)$. Структура морфологически представляет собой вулканический массив депрессионного типа практически округлой формы, достигающий в поперечнике 14 км. Вмещающими породами служат образования Горбушинского субтеррейна - фрагмента раннемеловой неокомской аккреционной призмы Таухинского террейна. Они представлены многократно повторяющимся разрезом кремнистых пород с остатками триасово-юрских микрофоссилий, согласно перекрытых преимущественно берриас-валанжинскими песчаниковыми турбидитами. [1, 2]. Новые изотопно-геохимические данные для вулканических комплексов Южно-Якутинской ВТС свидетельствуют об их образовании на границе палеоцен-эоцена: 54,3 $\pm 2,9$ млн лет [3]. В ряде работ было показано, что раннепалеогеновый магматический комплекс в пределах Сихотэ-Алиня (богопольский вулканический и якутинский плутонический комплекс) объединяет горные породы особого минерало-геохимического состава, которые резко отличаются от таковых предшествующего и последующего этапов магматизма. Этот комплекс характеризуется высокодифференцированным составом обогащенных летучими компонентами исходных магм и принадлежностью к магматическим породам А-типа [4-7].

Линейно-концентрические интрузивные тела Южно-Якутинской вулкано-тектонической структуры (ВТС) подчеркивают внутреннюю структуру изометрических кальдер обрушения и трещинный (по кольцевым сбросам) тип извержений. Широкое развитие пирокластических образований, развитие флюидальных и сферолитовых текстур в вулканических породах, наличие газовых полостей и миароловых пустот в лавах и центральных частях сферолоидов свидетельствуют о насыщенности исходных магм летучими компонентами. Южно-Якутинская ВТС относится к типу открытых магматических систем, в которой развитие игнимбритообразующего очага завершается взрывом и выбросом на поверхность магматической и газовой компонент. Субвулканические и экструзивные тела заключительных стадий магма- тизма относятся к типу условно закрытых (переходных) систем, где четко проявлены процессы близповерхностной дифференциации, отделения летучих компонентов и автометасоматическое изменение пород. Повышение кремнекислотности расплавов с одновременным накоплением щелочей, магмофильных: B, F и рудных компонентов, вплоть до появления аномальных высококремнистых, ультракалиевых риолитов, может быть обусловлено фильтрацией флюидов, связанной с быстрой потерей летучих компонентов в результате быстрого подъема магмы к земной поверхности. Логичным продолжением эволюции магматической системы является появление в постмагматический этап гидротермальных растворов - производных остывающего очага кислой магмы, обусловивших проявления различного типа минерализации в пределах ВТС. Необходимо отметить, что в прилегающих районах исследованной территории локализована золото-серебряная и бериллиевая с флюоритом минерализация [8].

Цель настоящего исследования состоит в выявлении лантаноидного тетраэдного эффекта в зависимости от содержаний флюидного компонента (F) на примере экструзивно-лавовых и пирокластических образований Южно-Якутинской ВТС.

\section{Материалы и методы исследования}

Определение содержания фтор-иона в горных породах выполнено ионометрическим методом с использованием фторидселективного электрода. Этот метод обладает высокой специфичностью к ионам фтора, прост в обращении, надежен и позволяет определять фторид-ион с чувствительностью от 0,05 мг/мл. Особенностью используемой методики является осаждение мешающих элементов (Al, Th, Be, Р3Э и др.) с малорастворимыми соединениями двухвалентного железа при $\mathrm{pH}=8,5-9,5$. Пробы предварительно сплавляли c $\mathrm{KNaCO}_{3}$ при температуре $850^{\circ} \mathrm{C}$ и выщелачивали горячей дистиллированной водой. Аликвоты фильтрата $\left(25 \mathrm{~cm}^{3}\right)$ нейтрализовали $\mathrm{HCl}(1: 1)$ по метиловому оранжевому с последующим добавлением ацетатного буферного раствора для установления необходимого рН 5,5. Растворы доводили дистиллированной водой до метки в мерных колбах вместимостью $50 \mathrm{~cm}^{3}$. Концентрацию фторид-иона выполняли измерением ЭДС ячейки, составленной из фторидного ЭЛИТ 221 и вспомогатель- 
ного хлор-серебряного ЭВЛ-1М3.1 электродов на иономере «IONOMETER I-500», Россия. Содержание $\mathrm{F}^{-}$определяли по градуировочному графику. Достоверность полученных результатов анализа на содержание фтор-иона подтверждена анализом стандартных образцов состава (ДВД-1, СГД-2А, ДВМ) и методом добавок известных концентраций фторид-иона в анализируемые растворы.

\section{Результаты исследования и их обсуждение}

Поведение микроэлементов в геохимических системах и их интерпретация основаны на фундаментальных параметрах: изовалентные микроэлементы с равными или очень сходными ионными радиусами должны оставаться тесно связанными в геологических процессах. Если нарушается геологическая система, то происходит прерывание когерентности «парных» элементов и появляется лантаноидный тетрадный эффект фракционирования РЗЭ. Это явление связано с нарушением формы спектра нормированных по хондриту содержаний редкоземельных элементов, выраженных в разделении всего спектра из 15 элементов на 4 группы (тетрады) с образованием зигзагообразной кривой: 1: La-Ce-Pr-Nd; 2: Pr-Sm-Eu-Gd; 3: Gd-Tb-Dy-Ho; и 4: Er$\mathrm{Tm}-\mathrm{Yb}-\mathrm{Lu}$. Для количественного определения тетрадного эффекта в настоящий момент используют только первую $\left(\mathrm{TE}_{1}\right)$ и третью $\left(\mathrm{TE}_{3}\right)$ тетрады. Вторая тетрада $(\mathrm{Pr}-$ Gd) малозаметна в связи как с отсутствием в природе $\mathrm{Pr}$, так и с исключительным поведением $\mathrm{Eu}^{2+}$ при низкой кислородной летучести и высоких температурах в магматических системах. Четвертая тетрада $(\mathrm{Er}-\mathrm{Lu})$ в основном является слабо развитой [9]. Лантаноидный тетрадный эффект впервые был установлен экспериментально при изучении экстракции редкоземельных элементов в системах водных фаз. Позднее он был отмечен как в магматических породах, так и в отложениях гидротермальных флюидов [10]. Существуют два различных типа тетрадных эффектов (М и W), относящихся к кривым REE c изогнутыми вверх и вниз линиями каждой тетрады соответственно. В гранитах известен только М-тип, в то время как $\mathrm{W}$-тип типичен для жидких фторидных фаз, отделяющихся от силикатных расплавов и/или минералов поздних стадий кристаллизации. Оба типа производны друг от друга и по определению являются зеркальными. Тетрад-эффект считается значимым при $\mathrm{TE}_{1-3}<0,9$ (W-тип) и $\mathrm{TE}_{1-3}>1,1$ (М-тип).

Данный эффект часто сопровождается другим модифицированным, так называемым не заряд-радиус-контролируемым (non-CHARAC) геохимическим поведением многих микроэлементов. «Чистые» силикатные расплавы характеризуются соответствием поведения заряд-радиусных характеристик микроэлементов, поэтому элементы с одинаковыми зарядом и радиусом демонстрируют согласованное поведение и сохраняют когерентность элементов, нормированных к хондриту, а нормированные графики (спайдер-диаграммы) представляют собой плавные функции ионных радиусов и атомных номеров. Высокодифференцированные составы магм, богатые такими компонентами, как $\mathrm{H}_{2} \mathrm{O}, \mathrm{Li}, \mathrm{B}, \mathrm{F}, \mathrm{P}$ и/или $\mathrm{Cl}$ [11], часто имеют некогерентное поведение REE типа non-CHARAC и нехондритовые соотношения $\mathrm{Y} / \mathrm{Ho}, \mathrm{La} / \mathrm{Nb}$ и $\mathrm{Zr} / \mathrm{Hf}$.

На примере редкоземельного состава пород Южно-Якутинской структуры нами рассчитаны значения тетрадного эффекта фракционирования РЗЭ и построены спайдер-диаграммы (таблица, рисунок). Значительные показатели тетрадного эффекта установлены в наиболее дифференцированных высококремнеземистых породах, в то время как показатель $\mathrm{TE}_{1-3}$ имеет меньшие величины в «низкокремнеземистых разностях», но при этом в F-обогащенных породах. В то же время оба типа пород Южно-Якутинской ВТС не характеризуются аномальными величинами содержания F (таблица).

Как известно, содержание F может быть достаточно низким в магматических породах, но это не соответствует его действительному содержанию в первичных расплавах. Даже небольшое количество F заметно влияет на минеральные равновесия и существенно мобилизует целый ряд редкометалльных элементов. На поздней стадии F перераспределяется исключительно во флюидную фазу, обедняя расплав по мере снижения температуры, и концентрируется в кристаллизующихся F-содержащих минералах [12].

В дальнейшем возможны разделение фторидных и силикатных расплавов в магматических очагах, внедрение силикатных расплавов во вмещающие породы и образование интрузивных, субвулканических или эффузивных пород с тетрад-эффектами М-типа в спектрах РЗЭ [13]. Как известно, 
F-комплексы являются важными переносчиками ряда элементов при формировании рудных гидротермальных месторождений $\mathrm{Sn}, \mathrm{W}, \mathrm{Mo}, \mathrm{Ta}, \mathrm{Nb}, \mathrm{Li}, \mathrm{P} 3 Э$ и Au и Ве $[14,15]$.

Согласно данным [16] обогащение системы F смещает эвтектические и котектические отношения кислого расплава в менее кремнекислотную область, богатую щелочами, подтверждая природный феномен Южно-Якутинской ВТС.

Одним из следствий полученных результатов является наблюдаемое значительное уменьшение концентраций $\mathrm{Zr}$ в высокодифференцированных порциях «высококремнеземистых» расплавов. В подобных случаях использование $\mathrm{Zr}$ в качестве одного из элементов дискриминантных диаграмм для выявления геодинамических обстановок проявлений магматических комплексов может привести к их ошибочной интерпретации [17]. В тех случаях, когда взаимодействие расплавфлюид вызывает тетрадный эффект и «нехарактерное» поведение микроэлементов, их тектоническая интерпретация не может быть корректной.

\section{Заключение}

На основании проведенных исследований можно сделать следующие выводы.

1. Приведенные материалы показывают наличие лантаноидного тетрадного эффекта М-типа в риолитах Южно-Якутинской ВТС.

2. Выявленный тетрадный эффект подтверждает факт эволюции магматической системы Южно-Якутинской ВТС в условиях аномального флюидного режима, что в свою очередь приводит к значительному перераспределению РЗЭ.

Микроэлементный состав (г/т) вулканических пород Южно-Якутинской ВТС

\begin{tabular}{|c|c|c|c|c|c|c|c|c|c|}
\hline \multicolumn{4}{|c|}{$\begin{array}{c}\text { «Никокремнеземистые» } \\
\text { риолиты }\end{array}$} & \multicolumn{3}{c|}{ «Высококремнеземистые» } \\
\hline $\mathrm{F}$ & 51 & 85 & 643 & 104 & 64 & 272 & 172 & 186 & 61 \\
\hline $\mathrm{Zr}$ & 124,73 & 108,14 & 276,12 & 171,16 & 217,47 & 187,08 & 106,05 & 148,24 & 244,24 \\
\hline $\mathrm{La}$ & 16,38 & 21,82 & 39,74 & 40,01 & 9,39 & 10,96 & 15,86 & 12,95 & 33,41 \\
\hline $\mathrm{Ce}$ & 47,08 & 66,63 & 78,83 & 63,63 & 61,68 & 74,38 & 62,13 & 53,18 & 73,93 \\
\hline $\mathrm{Pr}$ & 3,73 & 5,67 & 9,29 & 8,54 & 3,03 & 2,79 & 4,19 & 3,52 & 7,83 \\
\hline $\mathrm{Nd}$ & 12,98 & 18,24 & 33,21 & 30,53 & 12,99 & 9,89 & 15,47 & 13,45 & 27,84 \\
\hline $\mathrm{Sm}$ & 3,16 & 4,82 & 7,69 & 6,25 & 3,97 & 2,76 & 4,76 & 3,75 & 5,95 \\
\hline $\mathrm{Eu}$ & 0,36 & 0,48 & 0,90 & 0,74 & 0,44 & 0,09 & 0,14 & 0,15 & 0,62 \\
\hline $\mathrm{Gd}$ & 2,75 & 3,27 & 5,80 & 5,06 & 3,34 & 2,32 & 4,72 & 3,23 & 4,02 \\
\hline $\mathrm{Tb}$ & 0,52 & 0,59 & 1,01 & 0,92 & 0,72 & 0,45 & 1,04 & 0,71 & 0,70 \\
\hline $\mathrm{Dy}$ & 4,47 & 4,77 & 6,77 & 5,65 & 4,87 & 3,48 & 8,13 & 5,61 & 4,80 \\
\hline $\mathrm{Ho}$ & 0,91 & 0,85 & 1,20 & 1,02 & 0,93 & 0,65 & 1,48 & 1,27 & 0,86 \\
\hline $\mathrm{Er}$ & 3,18 & 2,91 & 3,86 & 3,49 & 3,31 & 2,29 & 4,70 & 4,36 & 2,57 \\
\hline $\mathrm{Tm}$ & 0,46 & 0,49 & 0,52 & 0,50 & 0,49 & 0,39 & 0,69 & 0,65 & 0,42 \\
\hline $\mathrm{Yb}$ & 3,07 & 3,18 & 3,62 & 2,95 & 2,85 & 2,38 & 3,84 & 3,89 & 2,15 \\
\hline $\mathrm{Lu}$ & 0,50 & 0,54 & 0,57 & 0,53 & 0,51 & 0,39 & 0,63 & 0,59 & 0,38 \\
\hline $\mathrm{Hf}$ & 5,31 & 5,84 & 5,46 & 5,53 & 5,62 & 5,03 & 5,33 & 5,83 & 6,24 \\
\hline $\mathrm{Ta}$ & 1,00 & 1,17 & 1,35 & 1,14 & 1,05 & 0,92 & 1,39 & 1,42 & 1,29 \\
\hline $\mathrm{Pb}$ & 23,47 & 24,14 & 24,85 & 23,04 & 11,10 & 43,80 & 36,36 & 26,24 & 29,20 \\
\hline $\mathrm{Th}$ & 17,30 & 17,63 & 18,51 & 18,46 & 12,24 & 14,38 & 17,11 & 17,60 & 15,92 \\
\hline $\mathrm{U}$ & 3,68 & 3,63 & 3,79 & 3,87 & 2,29 & 2,42 & 4,09 & 3,88 & 3,32 \\
\hline $\mathrm{TE}$ & 1,16 & 1,23 & 1,07 & 1,02 & 1,43 & 1,47 & 1,32 & 1,26 & 1,10 \\
\hline
\end{tabular}

П р и м е ч а н и е : геохимический состав из работы [3].

Степень тетрадного эффекта $=\mathrm{TE}_{1,3}=(\mathrm{t} 1 \mathrm{x} \mathrm{t3})^{0,5}[8]$, где $\mathrm{t} 1=\left(\mathrm{Ce} / \mathrm{Ce}^{\mathrm{t}} \mathrm{x} \mathrm{Pr} / \mathrm{Pr}^{\mathrm{t}}\right)^{0.5}$ и $\mathrm{t} 3=\left(\mathrm{Tb} / \mathrm{Tb}^{\mathrm{t}} \mathrm{x}\right.$ $\left.\mathrm{Dy} / \mathrm{Dy}^{\mathrm{t}}\right)^{0.5} \cdot \mathrm{Ce} / \mathrm{Ce}^{\mathrm{t}}=\mathrm{Ce}_{\mathrm{cn}} /\left(\mathrm{La}_{\mathrm{cn}}{ }^{2 / 3} \times \mathrm{Nd}_{\mathrm{cn}}{ }^{1 / 3}\right) ; \mathrm{Pr} / \mathrm{Pr}^{\mathrm{t}}=\mathrm{Pr}_{\mathrm{cn}} /\left(\mathrm{La}_{\mathrm{cn}}{ }^{1 / 3} \times \mathrm{Nd}_{\mathrm{cn}}{ }^{2 / 3}\right) ; \mathrm{Tb} / \mathrm{Tb}^{\mathrm{t}}=\mathrm{Tb}_{\mathrm{cn}} /\left(\mathrm{Gd}_{\mathrm{cn}}{ }^{2 / 3} \mathrm{x} \mathrm{Ho}_{\mathrm{cn}}{ }^{1 / 3}\right) ;$ $\mathrm{Dy} / \mathrm{Dy}^{\mathrm{t}}=\mathrm{Dy}_{\mathrm{cn}} /\left(\mathrm{Gd}_{\mathrm{cn}}{ }^{1 / 3} \mathrm{x} \mathrm{Ho}_{\mathrm{cn}}{ }^{2 / 3}\right) . \mathrm{Ln}_{\mathrm{cn}}=$ хондрит-нормализованные лантаноидные концентрации [11]. 

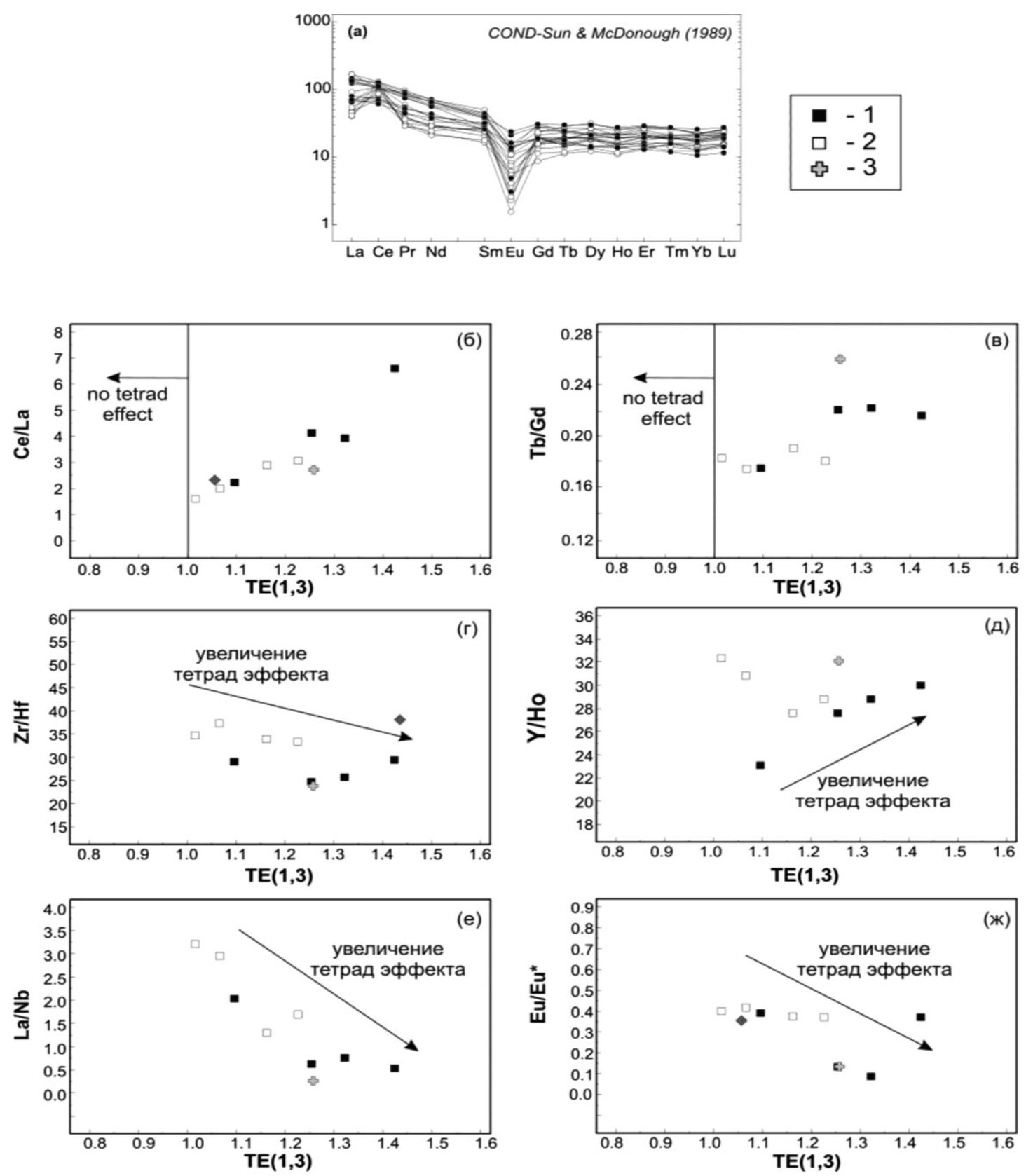

Составы вулканических пород Южно-Якутинской ВТС, нормированные по хондриту (а); вариационные диаграммы отночений элементов ключевых величин тетрад эффекта для «низкокремнеземистых» (1) и «высококремнеземистых» пород (2) и сферолита риолитовых лав Южно-Якутинской ВТС (3) (б-ж)

3. Флюидонасыщенные магматические расплавы Южно-Якутинской ВТС обладают потенциальной рудогенерирующей способностью. При проведении детальных поисковых работ необходимо учитывать парагенетическую связь флюоритовой с бериллием минерализации с наиболее дифференцированными породами раннепалеогеновых комплексов Сихотэ-Алиня.
Исследование выполнено при финансовой поддержке РФФИ в рамках научного проекта № 19-05-00100.

\section{Список литературы / References}

1. Kemkin I.V., Kemkina R.A. Comparative geochemical study of the cherty rocks of the Taukha terrane (Sikhote-Alin) and its paleogeodynamic significance. Acta geochimica. 2019. DOI: $10.1007 / \mathrm{s} 11631-019-00385-3$.

2. Кемкин И.В. Геохимическая характеристика кремниевых пород разновозрастных тектоно-стратиграфиче- 
ских комплексов Таухинского террейна (Сихотэ-Алинь): История дрейфа и динамика движения Палеотихоокеанской плиты // Успехи современного естествознания. 2019. № 6. C. $125-137$.

Kemkin I.V. Geochemical characteristics of the differentaged tectono-stratigraphic complexes of the Sikhote-Alin Taukha terrane: The histiry of drift and dynamics of movement of the Paleo-Pacific plate // Advances in current natural sciences. 2019. № 6. P. 125-137 (in Russian).

3. Гребенников А.В., Максимов С.О. Причины появления вулканических пород А-типа на активных окраинах континентов на примере Южного Сихотэ-Алиня (Дальний Восток России) // Геология и геофизика. 2020. [Электронный pecypc]. URL: https://www.sibran.ru/journals/issue. php?ARTICLE ID=178370 (дата обращения: 15.03.2020) DOI: $10.15372 / \mathrm{GiG} 2020114$.

Grebennikov A.V., Maksimov S.O. Reasons for the appearance of A-type volcanic rocks on the active margins of the continents on the example of Southern Sihote-Alina (Far East of Russia) // Geology and Geophysics. 2020. [Electronic resource] URL: https://www.sibran.ru/journals/issue.php?ARTICLE ID $=178370$ (date of access: 15.03.2020) (in Russian). DOI $10.15372 / \mathrm{GiG} 2020114$

4. Гребенников А.В., Попов В.К. Петрогеохимические аспекты позднемелового и палеогенового игнимбритового вулканизма Восточного Сихотэ-Алиня // Тихоокеанская геология. 2014. Т. 33. № 1. С. 41-57.

Grebennikov A.V., Popov V.K. Petrogeochemical Aspects of the Late Cretaceous and Paleogene Ignimbrite Volcanism of East Sikhote-Alin. Russian Journal of Pacific Geology. 2014. V. 8. № 1. P. 38-55. DOI: 10.1134/S1819714014010035.

5. Grebennikov, A.V., Khanchuk, A.I., Gonevchuk, V.G. Kovalenko, S.V., 2016. Cretaceous and Paleogene granitoid suites of the Sikhote-Alin area (Far East Russia): geochemistry and tectonic implications. Lithos. 2016. Vol. 261. P. 250-261. DOI: 10.1016/j.lithos.2015.12.020.

6. Гребенников А.В. Гранитоиды А-типа: проблемы диагностики, формирования и систематики // Геология и геофизика. 2014. Т. 55. № 9. С. 1356-1373.

Grebennikov A.V. A-type granites and related rocks: petrogenesis and classification. Russian Geology and Geophysics. 2014. V. 55. № 9. P. 1074-1086. DOI: 10.1016/j.rgg.2014.08.003.

7. Martynov Yu.A., Khanchuk A.I., Grebennikov A.V., Chashchin A.A., Popov V.K. Late Mesozoic and Cenozoic volcanism of the East Sikhote-Alin area (Russian Far East): A new synthesis of geological and petrological data. Gondwana research. 2017. Vol. 47. P. 358-371. DOI: 10.1016/j.gr.2017.01.005.

8. Коваленко А.П., Журавлев В.Н., Коваленко Р.А О бертрандитовой минерализации в молодых вулканогенных образованиях // Геология рудных месторождений. 1968 T. 10. № 5. C. 87-90.

Kovalenko A.P., Zhuravlev V.N., Kovalenko R.A. On bertrandite mineralization in young volcanogenic formations // Geologiya rudny`x mestorozhdenij. 1968. Vol. 10. № 5. P. $87-$ 90 (in Russian).

9. IrberW. The lanthanide tetrad effect and its correlation with $\mathrm{K} / \mathrm{Rb}, \mathrm{Eu} / \mathrm{Eu}^{*}, \mathrm{Sr} / \mathrm{Eu}, \mathrm{Y} / \mathrm{Ho}$ and $\mathrm{Zr} / \mathrm{Hf}$ of evolving peraluminus granite suites. Geochimica et cosmochimica acta. 1999. Vol. 63 P. 489-508. DOI: 10.1016/S0016-7037(99)00027-7.

10. Гусев А.И. Петрология, геохимия и рудоносность анорогенных гранитоидов шибеликского комплекса Горного
Алтая // Известия Томского политехнического университета. Инжиниринг георесурсов. 2016. Т. 327. № 6. С. 71-82.

Gusev A.I. Petrology, geochemistry and ore mineralization of anorogenic granitoids of Shibelikskii complex in Gorny Alatai // Izvestiya Tomskogo politexnicheskogo universiteta. Inzhiniring georesursov. 2016. V. 327. № 6. P. 71-82 (in Russian).

11. Jahn B.-M., Wu F., Capdevila R., Martineau F., Zhao Z., Wang Y. Highly evolved juvenile granites with tetrad REE patterns: the Woduhe and Baerzhe granites from the Great Xing'an Mountains in NE China. Lithos. 2001. V. 59. P. 171-198.

12. Коренева В.Н., Зарайский Г.П., Граменицкий Е.Н. Экспериментальное изучение фазовых соотношений в системе Na-Al-Si-O-F-H O при T $=800^{\circ} \mathrm{C}$ и $\mathrm{P}=1$ кбар, в зависимости от концентрации воды // Экспериментальная минералогия. 2004. T. 2. С. 125-134.

Koreneva V. N., Zaraysky G.P., Gramenitsky E.N. An experimental study of phase relationships in the Na-Al-Si-O$\mathrm{F}-\mathrm{H}_{2} \mathrm{O}$ system at $\mathrm{T}=800^{\circ} \mathrm{C}$ and $\mathrm{P}=1 \mathrm{kbar}$, depending on the concentration of water // Experimental mineralogy. 2004. V. 2. P. 125-134 (in Russian).

13. Перетяжко И.С., Савина Е.А. Тетрад-эффекты в спектрах распределения редкоземельных элементов гранитоидных пород как индикатор процессов фторидно-силикатной жидкостной несмесимости в магматических системах // Петрология. 2010. Т. 18. № 5. С. 536-566.

Peretyazhko I.S., Savina E.A. Tetrad effects in the distribution spectra of rare-earth elements of granitoid rocks as an indicator of fluoride-silicate liquid immiscibility processes in magmatic systems. Petrology. 2010. V. 18. № 5. P. 514-543. DOI: $10.1134 / \mathrm{S} 086959111005005 \mathrm{X}$

14. Гусев А.И., Гусева А.А. Тетрадный эффект фракционирования редкоземельных элементов и его использование в решении проблем петрологии гранитоидов // Успехи современного естествознания. 2011. № 5. С. 45-49.

Gusev A.I., Guseva A.A. The tetrad effect of fractionation of rare-earth elements and its use in solving the problems of petrology of granitoids // Advances in current natural sciences. 2011. № 5. P. 45-49 (in Russian).

15. Гвоздев В.И., Гребенникова А.А., Вах А.С., Горячев Н.А., Федосеев Д.Г. Эволюция процессов минерало-образования при формировании золото-редкометалльных руд Средне-Голготайского месторождения (Восточное Забайкалье) // Тихоокеанская геология. 2020. Т. 39. № 1. С. 70-91. DOI: 10.30911/0207-4028-2020-39-1-70-91

Gvozdev V.I., Grebennikova A.A., Vakh A.S., Goryachev N.A., Fedoseev D.G. Evolution of mineral formation process under formation of gold-rare-metal ores in Sredne-Golgotay deposit (Eastern Transbaikalia) // Russian journal of pacific geology. 2020. Vol. 39. № 1. P. 70-91. DOI: 10.30911/0207-40282020-39-1-70-91 (in Russian).

16. Manning D.A.C. The effect of fluorine on liquidus phase relationship in the system Qz-Ab-Or with excess water at $1 \mathrm{~kb}$. Contributions to mineralogy and petrology. 1981. Vol. 76. P. 206-215.

17. Jahn B.-M., Valui G., Kruk N., Gonevchuk V., Usuki M., Wu J.T.J. Emplacement ages, geochemical and $\mathrm{Sr}-$ $\mathrm{Nd}-\mathrm{Hf}$ isotopic characterization of Mesozoic to early Cenozoic granitoids of the Sikhote-Alin Orogenic Belt, Russian Far East: crustal growth and regional tectonic evolution. Journal of asian earth sciences. 2015. Vol. 111. P. 872-918. 